\title{
The Minimum Agriculture-Chunk as an Elementary Data Science Component in ADAM, a Micro Targeted, Trainable, Modular, Multipurpose System for Land
}

\section{Farming}

\author{
Panagiotis Serdaris, Konstantinos Spinthiropoulos, Michael Agrafiotis \\ Department of Business Administration, West Macedonia Univ of Applied Sciences, 50100 \\ Kozani, Greece \\ Athanasios Zisopoulos \\ Faculty of Mathematics and Informatics, University of Sofia Saint Kliment Ochridsky, Blvd \\ James Bourchier 5, 1164 g.k. Lozenets, Sofia, Bulgaria. \\ E-mail: zisopoulos.athanasios.dim@gmail.com
}

Received: November 15, 2018

doi:10.5296/jas.v6i4.14116
Accepted: December 9, 2018

URL: https://doi.org/10.5296/jas.v6i4.14116

\begin{abstract}
The poor Data Science support of agriculture brought us to our main idea of the research is to analyze all micro-works for every plant or tree. Then we proceed to specify targeted actions for harvest collection, micro spraying and hundreds similar simple actions. Initially we collect data from the farm. The airborne, land and underwater unmanned vehicles scan the field area with customized various sensors and cameras in various multi spectral modes. The result is minimum agro-chunk Four-Dimensional model. The unmanned vehicle on the field area receives target data. It is equipped with a general-purpose robotic arm, an absorbing bellow, a robotic pruner, a liquid spraying pipe, an underwater robotic arm and hundreds of others. It moves there and performs the commanded action. Action is flower or nuts collection, insect suction pruning and hundred more. All operations are high trainable by human intervention and the system stores its approach and logic for future action correction.
\end{abstract}

Keywords: data science, minimalism, agriculture, cultivation, harvest, sensors, robots, full spectrum, aeronautical operations, blockchain, insurance, data science, internet of things, $\mathrm{R}$ language, data analytics 


\section{Mll Macrothink}

Journal of Agricultural Studies

ISSN 2166-0379

2018, Vol. 6, No. 4

\section{Introduction}

Management is the absolute useful science while is not a real science. Management is not an exact science in terms of advanced algorithms and complicated nonsense talking. (Hegarty 2006, Helmer 1959, Jordan 1992).

The human mind is by far more advanced than any model could predict. Inventive minds and engineering exceed exponentially this unpredicting creative thinking. (Godfrey 1998, Obermeyer 2017, Arciszewski 2018, Cavallucci 2015)

In our case the agriculture machinery has initially very distinct specifications summarizing in: too heavy, to bulky, too late, too energy intensive, too much effort for a tiny result. In nature the harvest is simple, in time, no resources or energy is wasted. A bird harvests a cherry with a simple feather flap. There were hundreds of similar solutions for the moment Adam deported from Eden. Every inventor insists on his development but the only new good idea is to build on top of existing market solutions.

The main idea of the invention is to analyze all micro-works for every plant or tree. Then we proceed to specific targeted actions for harvest, pesticide micro spraying and hundreds similar simple primitive actions.

Current technology does not offer all type of agriculture robotic support primarily for reasons like:

- At old good times a tool was capable to accomplish a lot of agro-work. Today we face total Absence of co-integration.

- The robotic systems in use today are not made for the next negation of farmer intelligence.

- Very heavy robust machinery is used, for example to collect a few grammars nut.

- Our solution is to focus on a single very simple agro-work every time with light machinery under the guidance of an expert system and distributed tele-computer.

Our research technical field area is:

- Innovative Agriculture management, (Le Gal 2011, Hartemink 2008)

- Drone technology and applications, (Pobkrut 2016, Stehr 2015, Malveaux 2014)

- Submarine technology and applications ( Ford 1961, Scurlock 1976)

- Expert system knowledge representation for military operations and remote sensing (Rokhmana 2015, Sahoo 2015, Zhang 2014)

- Food technology traceability (Badia 2015, Karippacheril 2017)

- Blockchain agro insurance (Zisopoulos 2018, Kanavas 2016)

Bible research lemma from Old Testament, Genesis 3: (Thackeray 1911) in the dominated languages is: 
Table 1, ADAM the first farmer

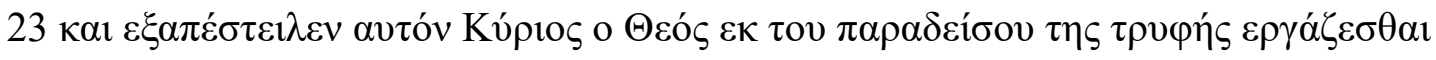
$\tau \eta \nu \gamma \eta \nu \varepsilon \xi \eta \varsigma \varepsilon \lambda \eta \dot{\varphi} \theta \eta$

23therefore the Lord God sent him forth from the garden of Eden to till the ground from which he was taken.

We decided to give a name this new photovoltaic after the first farmer without tools and trained by the angels, ADAM.

\section{Drawings}

To describe our research invention, we attach 4 drawings. The figurer 1 , describes the conceptual operation schema and field application of the invention, number 2 describes the filed vehicles drawing 3 describes the work head and invention usage.

\subsection{Conceptual Schema}

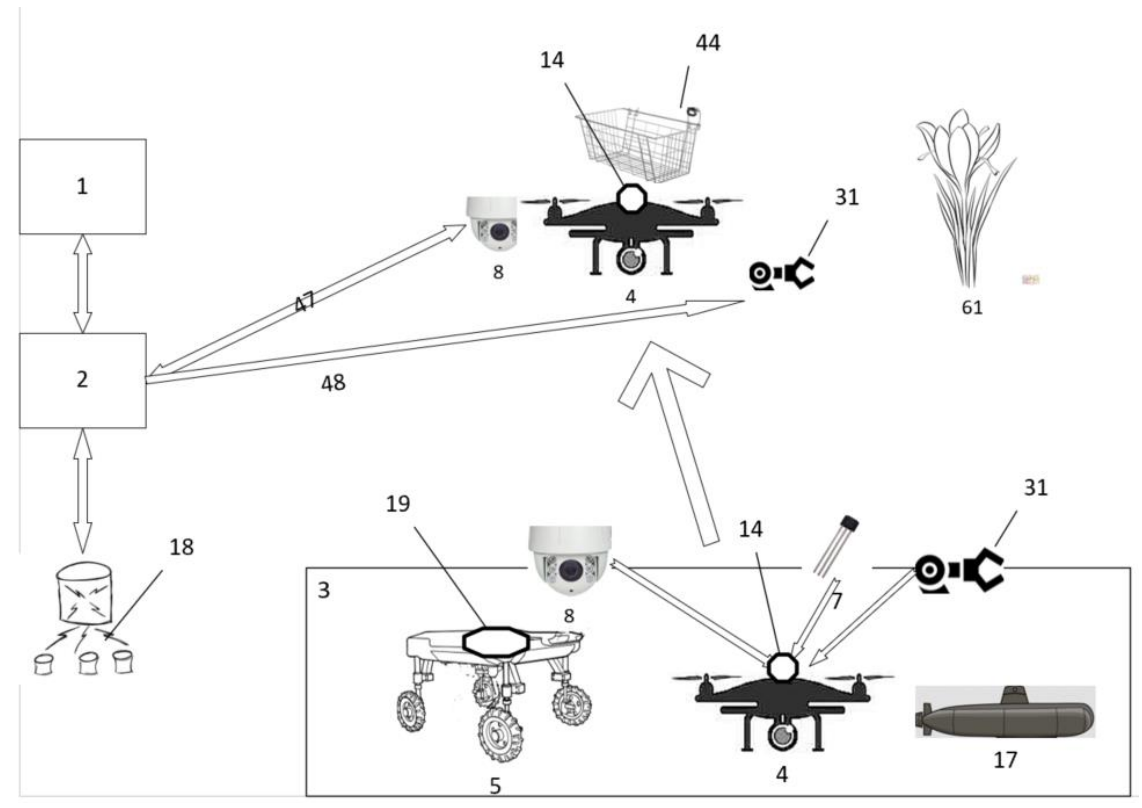

Figure 1. The conceptual invention subsystems interoperability

Drawing parts are:

- the address and mission calculation expert system (1),

- into a distributed sophisticated tele computer (2),

- with appropriate four-dimensional database schema (18)

- an airborne (4) field carrier (3)

- a land vehicle (5) field carrier (3) 


\section{Macrothink}

- an unmanned submarine (17) underwater carrier (3)

- with sockets (14) to mount various systems

- an on-vehicle monitoring subsystem (6)

- with full spectrum surveillance sensors (7)

- $\quad$ and cameras (8)

- multiple interchangeable work heads (9) for the targeted farm-work.

- Work head general socket (19)

- $\quad$ The flower to be collected (61)

\subsection{Mission Control}

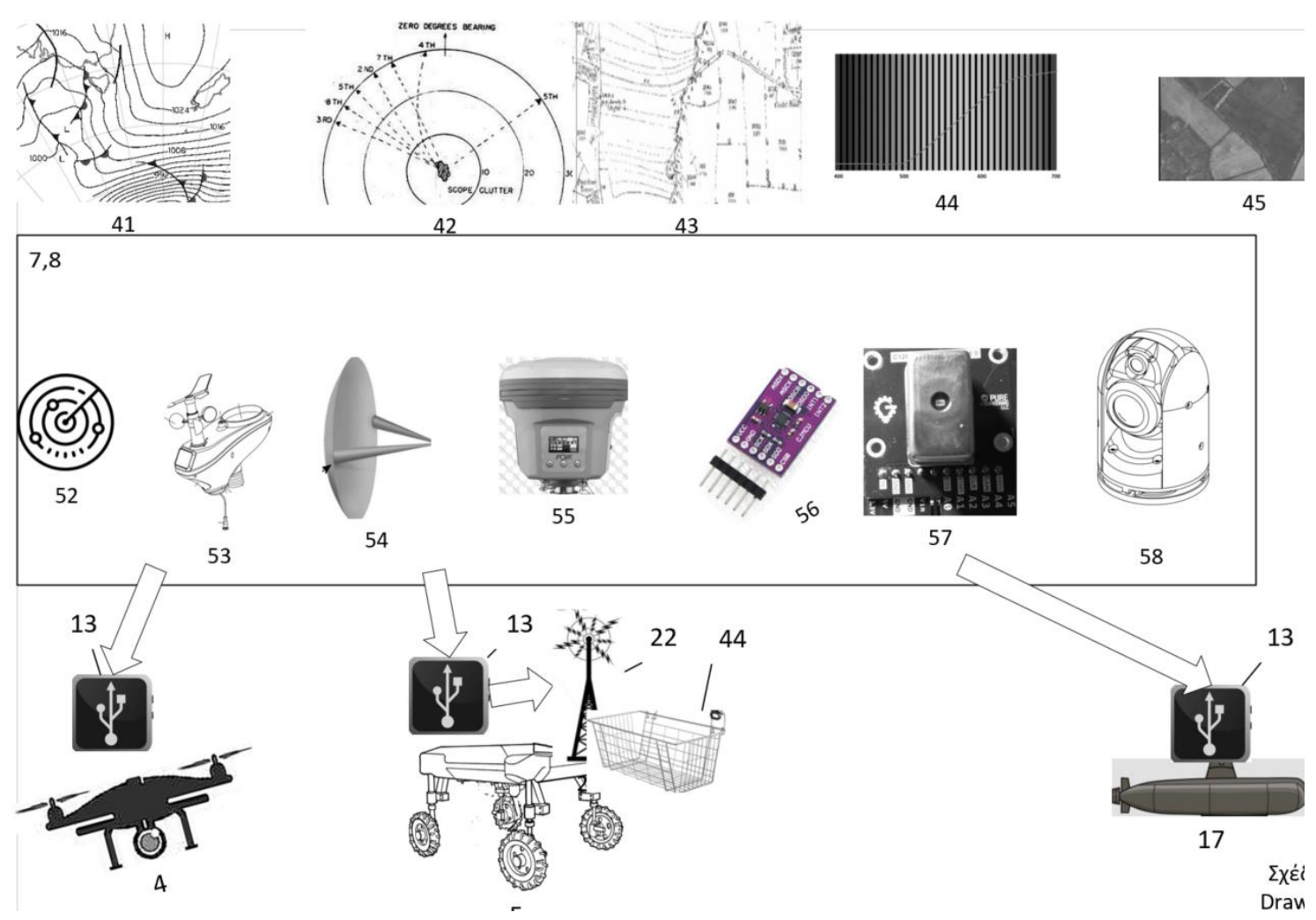

Figure 2. The on-field carrier (3), sensors (7) and cameras (8)

In the above figure 2 we describe the on-field carrier:

- a general-purpose unmanned field vehicle (5),

- an appropriately sized drone (4)

- $\quad$ or an unmanned submarine (17);

- $\quad$ the rural telecom system (22)

- the RFID traceable transport basket (44) 
- primarily electronics bus modular socket for sensors and cameras (13)

- mounted cameras (8)

- interchangeable sensors (7)

- Weather radar (52)

- Weather station (53)

- Approach radar (54)

- Differential Global Positioning System (55)

- inertial measurement unit (56)

- Photo spectrometer with wide range of light wave lengths (57)

- Still HD thermal camera (58)

- video camera (59)

- digital output to the computer (2) weather data (41), radar data (42), land cartography data (43), spectrogram (44), land thermal map (45)

\subsection{War Heads Interoperability}

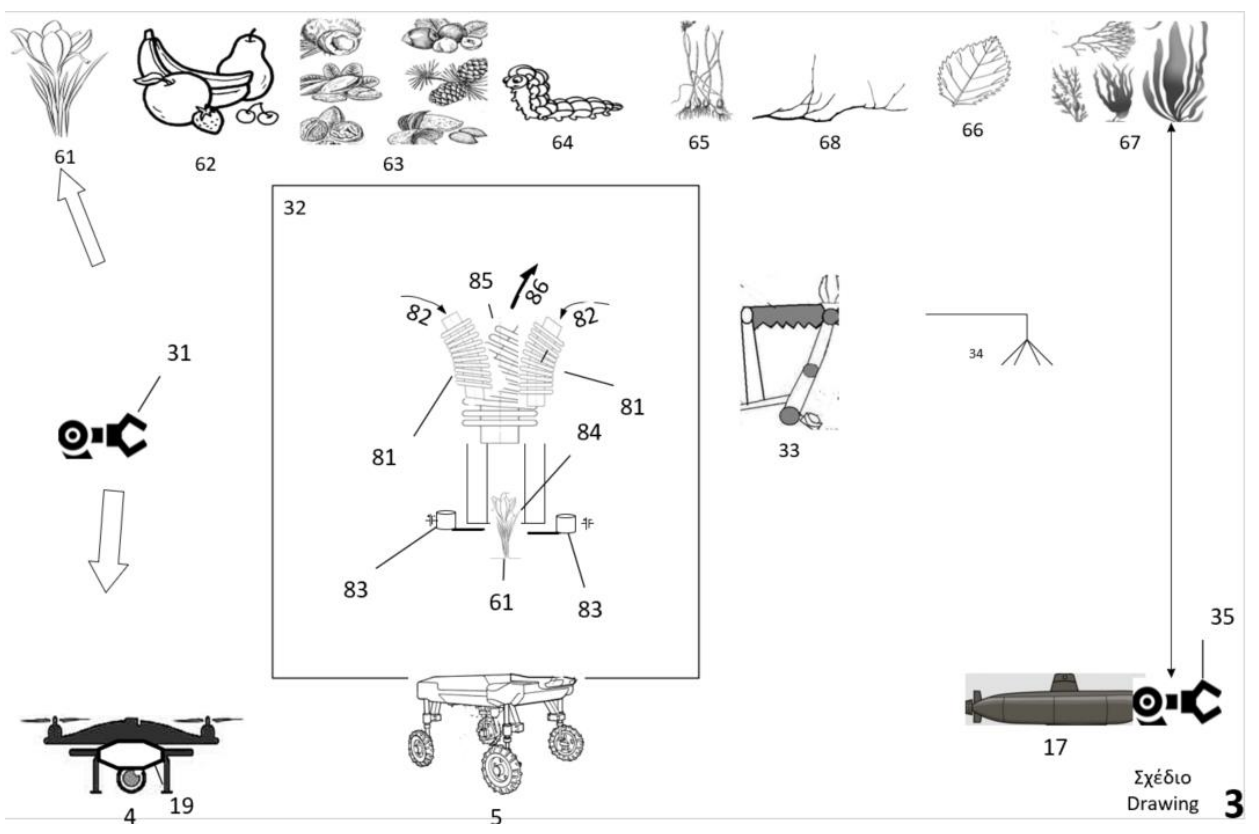

Figure 3. The interchangeable work heads

Work head operability is:

- Primarily electro mechanic Modular socket for work head (19)

- a general-purpose robotic arm (31) capable of grab, twist, and cut operation from flower-harvest collection to weed uprooting; 


\section{Macrothink}

Journal of Agricultural Studies

ISSN 2166-0379

2018, Vol. 6, No. 4

- an absorbing bellow dual air intake flexible cylinder (32) for flower, insect and worm collection; outer pipe (81) from the pipe-in a pipe mechanism;

- inner pipe (85); Air flow direction in the outer pipe (82); Inside out air flow direction in the inside pipe (86); Shutter-cuter knife (83); Cutting point (84)

- a robotic pruner (33) for tree pruning;

- a liquid spraying pipe for targeted micro pesticides or water targeted spraying (34);

- an underwater cultivated seaweed-algae harvesting robotic arm (35);

\section{General Functionality}

The general functionality of the invention is very similar to an aeronautical invasion and it is a peaceful transfer to land and sea farming. There are two type of field operations and two headquarter operations and an everlasting training option.

The first field operation surveillance is the data collection a four-dimensional multi spectral model of the farm constituting parts. The airborne vehicles scan the agro-field area with various sensors and cameras. They only send online or offline their data to the headquarters.

The first headquarter operation agro chunk definition analyzes spatiotemporal multispectral data. Such an analysis is actually the farmer work of the future. The result of minimum agro-chunk is a 4Dimensional model of the land field.

The second and final field operation, the agro-work, starts when our unmanned vehicle are placed on the field area. The airborne-wheel or submarine vehicle receives target data. It moves there and performs the commanded action. Action here is a nuts collection or an insect suction and mission accomplished.

The second headquarter operation, the vehicle guidance, is to guide the vehicle to the target and trims the mission data in real time in accordance the moving vehicle surveillance sensors and cameras.

All operations are high trainable by human intervention and subsequently stored logic for future action correction.

The invention looks futuristic but it is only a stripped-out version of old technologies and software. The general functionality of the invention has four steps.

\subsection{Surveillance}

For the first field operation surveillance a vehicle (3) is equipped with a monitoring subsystem (6), with full spectrum surveillance sensors (7), and cameras (8) (Drawing 1,2). Then it reaches the designation area and starts recording local the land farm. When the surveillance finishes the vehicle returns and unloads data to the central computer (2). This operation could be done any time additional data are required and/or during the productive second field operation. 


\section{Macrothink}

\subsection{The First Headquarter Operation}

The first headquarter operation minimum agro-chunk definition is the cornerstone of the invention. For every plant or tree a specific work must be done different in space and time even for the same plant. The minimum chunk is the exact piece of the plant to manipulated. A saffron plant has only one chunk and one action to be done: the flower to be cut or twisted. A tree has more chunks with different associated actions for every chunk:

- A worm (64) on a branch is sucked by the absorbing bellow (32)

- An unnecessary sprout (68) is cut by the robotic pruner (33)

- A leaf with a disease is micro sprayed with pesticide with a liquid spraying arm (34)

- A fruit with appropriate color (62) is collected by appropriate third part hardware.

The exact recognition is a complex, sophisticated, everlasting work. It uses various digital models $(41,42,43,44,45)$ brought in by the Weather radar (52), Weather station (53), Approach radar (54), Differential Global Positioning System (DGPS) (55), inertial measurement unit (56), Photo spectrometer with wide range of light wave lengths (57), still thermal camera (58), video camera (59) in a 4dimension model. The techniques to combine these data are Hyperspectral Imagery Analysis, Full Spectral Imaging and Multispectral pattern recognition (Isa 2017, Blasch 2014).

The result of all these is a database spanned on space any time with all millions of agrochunks in a typical farm. The definition of course is not static but dynamic until the time of operation over the agro chunk. Subsequently unforeseen algorithms are required to preserve agro-chunk integrity indicatively factors like:

- non-proportional Byzantine time of the day usage for light conditions.

- Meteorology data primarily wind and temperature.

- Plant growing.

The agro chunk actual location it will be proven enough reliable to start the next step.

\subsection{Second Field Operation}

The second and final field operation, the agro-work is easier than the above complexity. Once the action over the agro-chunk is decided we execute simple steps:

- The expert system (1) through the computer (2) advices the appropriate mission configuration.

- $\quad$ On the selected vehicle (3) we load the sensors a camera $(6,7)$ and the appropriate work heads (9)

- $\quad$ The vehicle proceeds to the chunk location and the computer $(1,2)$ reevaluates the exact possibilities of success.

- $\quad$ The work head (3,31,32,33,34 etc.) performs the operation and the use the basket (44) if applicable. 
The second headquarter operation, the vehicle guidance is a real time task during which the expert system receives online information from sensor $(7,8)$. Then it sends data to micro trim the guidance operation to adapt to the actual local situation.

All operations are high trainable due to the human superiority on some tasks. Machine training operation is simple in our days. During this phase a farmer guides the vehicle and work heads using all system components. If such guidance was efficient is stored in the expert system memory. Actually, all actions of the work head have been repeated at the training stage.

A simple example for saffron collection would clarify the invention usage. The drone fleet overflies on the land fields. As a result, the expert system $(1,2,3)$ has every flower position in the county in time and space positioning. We chose the unmanned surface vehicle (5) as more efficient due to extreme weather conditions. On top of the vehicle we mount a simple HD camera, a thermographic camera (58) and the absorbing bellow dual air intake flexible cylinder (32). We transport the vehicle to the field with saffron flowers and establish the connection to the computer (2) though the rural telecom (22). All system is turned on and the vehicle goes to the first flower (61). The cameras capture and send the photo to the expert system (1). The current image and associated data are compared with the stored minimum chunk image and the knowledge base. The computer proceeds to micro modifications and the work head (32) cuts the flower (61) and stores it to the basket (44). When the basket is full it is collected by the farmer. The basket has RFID and it is fully identified and traceable until the product reaches the final consumer. It is also useful for cooperative association logistics and payments.

The main invention problem is the expert system (1) since it needs a lot of time an investment to be realized. At the engineering stage of the invention alpha test a number of parts will be replaced by more efficient subsystems.

The invention is capable to accomplish extraordinary harvest options. New profitable applications are possible:

- Edelweiss flower collection, impossible to approach today since they only grow in high unapproachable mountains.

- Targeted pesticide micro spray on a flower stigma flower part, hand accuracy and vision are adequate.

- With drone grabbing bee cells could easily be placed and maintenance in inaccessible virgin mountain places.

- Under water fish or plant farm with all extreme environment that the deep salt water is.

Most the electric and mechanic parts are commercially available from the industry today but there are a lot of implementation details to be solved, both at a technical and cost benefit level. 


\section{Legislative Description}

The micro targeted, trainable, modular, multipurpose system for agriculture work is characterized by its principal function to address to the smallest spatiotemporal possible agro-chunk(10), a mission calculation expert system(1), a distributed sophisticated tele computer(2), a farm field carrier (3) with sockets to mount various systems (14), an on vehicle monitoring subsystem (6), with full spectrum surveillance sensors (7) and cameras (8) and multiple interchangeable work heads (9) for the targeted farm-work.

The smallest possible agro-chunk (10) according the above main claim is characterized by the lowest possible level addressable farm co-integrated element like: flower, fruit, nuts, weed, insect, leave, sprout, algae and thousands of others.

The address and mission calculation expert system (1) according the above main claim is characterized by its focus on the final destination at the smallest possible chunk (10), agro-chunk recognition algorithms, actual chunk behavioral spatiotemporal position, dual operation status actual harvesting (11) and training (12), mission data calculation and finally transmission to the field carrier (3).

The training operation (12) in claim 3 is characterized by accumulative knowledge given by thousands hand operated tasks performed through all the system monitoring and work heads $(6,7,8,9)$ through which the system (1) understands and incorporates all details into its algorithmic knowledge and future action.

The distributed sophisticated tele computer (2) according the above main claim is characterized by a high-performance heavy duty distributed tele computer with industrial Internet of things rural radio (22), Hyperspectral Imagery Analysis, Full Spectral Imaging, Multispectral pattern recognition and spatiotemporal chunk (10) data storage (41).

The on-field carrier (3), according the above main claim is characterized by an appropriately sized drone (4) or a general-purpose unmanned field vehicle (5), or an unmanned submarine (17); all three are equipped with the rural telecom system (22) and modular sockets (13) into where are mounted cameras, interchangeable sensors $(7,8)$ and work-heads (9) depending from the mission to be accomplished.

The vehicle monitoring subsystem (6) according the main claim is characterized by full spectrum surveillance sensors (7) and cameras (8) for video and still recording at full spectrum with infrared, visible violet coverage.

The multiple work head (9) according to the above main claim is characterized by the following pairs of agriculture machinery; a general purpose robotic arm (31) capable of grab, twist, and cut operation from flower-harvest collection to weed uprooting; an absorbing bellow dual air intake flexible cylinder(32) for flower, worm collection; a robotic pruner(33) for tree pruning; a liquid spraying pipe for targeted micro pesticides or water targeted spraying(34); an underwater cultivated seaweed-algae harvesting robotic arm (35); etc. 


\section{Conclusion, Data Analytics Information Collection in Agriculture With Minimum} Agro Chunk

The technology presented above denotes general implementation details from the basic minimum addressable agro-chunk approach. It concerns an open architecture derived from military operations into which will be fitted various components. The trilateral nature of time give us the three different steps:

- Historical data; as manifestations of breeding and harvest, realized in $\mathrm{R}$ mathematical programming Language.

- Action Data; Things to do today actions implemented in Matlab-Simulink programming language.

- Future calculation data; New data variations for the future will be based in Python Environment.

\subsection{Past Historical Cultivation Data}

Historical data is used from Data Science analytics for initial model algorithms. Various scientists propose different approaches. Most researchers focus on trivial traditional government understood agriculture data.

This old-fashioned approach for past cultivation and harvesting data has the exact meaning of history. New devices need their own data. Huang (2018) described earth-observation BIG data and analysis daily from the platforms, manned/unmanned aircrafts, and ground-based sensors. Pham (2018) started the discussion about the interaction between data analytics and competitive analysis either by focusing on micro-level firm capabilities or other macro-level industry competitiveness of firms in agricultural markets. Agriculture is undergoing a tremendous transformation in the collection and use of data to inform smarter farming decisions. Most of them focus also on big data analytics (Zhang 2019, Antle 2017, Jones 2017, Libe 2018, Janssen 2017, Kamilari 2107) while Sbarina (2015) uses a pure mathematical approach for Big Data in precision Agriculture.

Unfortunately, Data Science cannot help in non-repetitive agriculture tasks variations. Real inventive intelligence is required that only human brain has.

\subsection{Action Data}

All history is processed to prepare the current time instance action data think to do now. Action data is a simple four-dimensional array ( $\mathrm{x}, \mathrm{y}, \mathrm{z}, \mathrm{time}$ ) for every warhead regarding the procedure to achieve cultivation tasks. We found incapable Microsoft robotics developer studio for a multi-robot system, although they support both local and global maps in the reconstruction of a virtual scenario. (Matta 2014).

Closer to our mathematical approach is RobotiCad as a Matlab/Simulink toolbox for the robotics modeling and simulation ( Falconi 2008). Other researchers focus on guidance road maps ( Oksane 2016, Rein 2016) but there is not a standard in the foreseen future. Then we chose our reliable Matlab programming with old fashioned functions. 


\subsection{New Big Data}

After the agriculture field action (seed, pruning, harvest) a new generation of big data is generated. The mission data are processed and feed irrevocable various ADAM modules for future use. The big difference is that we now have realization data, the huge difference between theory and implementation. This realization is our only concern in commercial system design. (Rupnik 2018, Jones 2017, Oksanen 2016, Reina 2016)

\section{References}

Antle, J. M., et al. (2017). Next generation agricultural system data, models and knowledge products: Introduction. Agricultural Systems, 155, 186-190.

https://doi.org/10.1016/j.agsy.2016.09.003

Arciszewski, T. (2018). Morphological Analysis in Inventive Engineering. Technological Forecasting and Social Change, 126, 92-101. https://doi.org/10.1016/j.techfore.2017.10.013

Badia-Melis, R., Mishra, P., \& Ruiz-García, L. (2015). Food traceability: New trends and recent advances. A review. Food Control, 57, 393-401.

https://doi.org/10.1016/j.foodcont.2015.05.005

Blaschke, T., Hay, G. J., Kelly, M., Lang, S., Hofmann, P., Addink, E., .. \& Tiede, D. (2014). Geographic object-based image analysis-towards a new paradigm. ISPRS journal of photogrammetry and remote sensing, 87, 180-191.

https://doi.org/10.1016/j.isprsjprs.2013.09.014

Cavallucci, D., et al. (2015). Assisting Decisions in Inventive Design of Complex

Engineering Systems. Procedia Engineering 131, 975-983.

https://doi.org/10.1016/j.proeng.2015.12.409

Falconi, R., \& C. Melchiorri (2008). RobotiCad: an Educational Tool for Robotics. IFAC Proceedings Volumes 41(2), 9111-9116. https://doi.org/10.3182/20080706-5-KR-1001.01538

Ford, E. H. (1961). U.S. Patent No. 2,989,945. Washington, DC: U.S. Patent and Trademark Office.

Godfrey-Smith, P. (1998). Complexity and the Function of Mind in Nature. Cambridge University Press.

Hartemink, A. E., \& McBratney, A. (2008). A soil science renaissance. Geoderma, 148(2), 123-129. https://doi.org/10.1016/j.geoderma.2008.10.006

Hegarty, C. (2006). It's not an exact science: teaching entrepreneurship in Northern Ireland. Education+ Training, 48(5), 322-335. https://doi.org/10.1108/00400910610677036

Helmer, O., \& Rescher, N. (1959). On the epistemology of the inexact sciences. Management Science, 6(1), 25-52. https://doi.org/10.1016/S2095-3119(17)61859-8

Hu, Q., Lv, S., Shi, Z., Sun, L., \& Xiao, L. (2017, June). Defense Against Advanced Persistent Threats with Expert System for Internet of Things. In International Conference on Wireless 
Algorithms, Systems, and Applications (pp. 326-337). Springer, Cham. https://doi.org/10.1007/978-3-319-60033-8_29

Huang, Y., et al. (2018). Agricultural remote sensing big data: Management and applications. Journal of Integrative Agriculture 17(9), 1915-1931.

https://doi.org/10.1016/S2095-3119(17)61859-8

Isa, H. L., Saad, S. A., Hisham, A. A. B., \& Ishak, M. H. I. (2017, August). Improvement of GPS Accuracy in Positioning by Using DGPS Technique. In Asian Simulation Conference (pp. 3-11). Springer, Singapore. https://doi.org/10.1007/978-981-10-6502-6_1

Janssen, S. J. C., et al. (2017). Towards a new generation of agricultural system data, models and knowledge products: Information and communication technology. Agricultural Systems 155: 200-212. https://doi.org/10.1016/j.fcr.2018.09.001

Jones, J. W., et al. (2017). Brief history of agricultural systems modeling. Agricultural Systems, 155, 240-254. https://doi.org/10.1016/j.agsy.2016.05.014

Jones, J. W., et al. (2017). Toward a new generation of agricultural system data, models, and knowledge products: State of agricultural systems science. Agricultural Systems, 155, 269-288. https://doi.org/10.1016/j.agsy.2016.09.021

Jordan, M. I., \& Rumelhart, D. E. (1992). Forward models: Supervised learning with a distal teacher. Cognitive Science 16(3): 307-354.

Kamilaris, A., et al. (2017). A review on the practice of big data analysis in agriculture. Computers and Electronics in Agriculture, 143, 23-37.

https://doi.org/10.1016/j.compag.2017.09.037

Kanavas V, Athanasios, Z., \& Papangelou, S. (2018). Small Forensic Smart-Law-Scripts the First Step for Intelligent Justice Punishment in Law Enforcement, Economic Crime and Alternative Sentences. Business and Economic Research, 8(2), 154-167.

https://doi.org/10.5296/ber.v8i2.13045

Karippacheril, T. G., Rios, L. D., \& Srivastava, L. (2017). Global markets, global challenges: Improving food safety and traceability while empowering smallholders through ICT. https://doi.org/10.1596/978-1-4648-1002-2_Module11

Le Gal, P. Y., Dugué, P., Faure, G., \& Novak, S. (2011). How does research address the design of innovative agricultural production systems at the farm level? A review. Agricultural Systems, 104(9), 714-728. https://doi.org/10.1016/j.agsy.2011.07.007

Liben, F. M., et al. (2018). Crop model and weather data generation evaluation for conservation agriculture in Ethiopia. Field Crops Research 228, 122-134.

https://doi.org/10.1016/j.fcr.2018.09.001

Lokers, R., et al. (2016). Analysis of Big Data technologies for use in agro-environmental science. Environmental Modelling \& Software, 84, 494-504.

https://doi.org/10.1016/j.envsoft.2016.07.017 
Malveaux, C., Hall, S. G., \& Price, R. (2014). Using drones in agriculture: unmanned aerial systems for agricultural remote sensing applications. In 2014 Montreal, Quebec Canada July 13-July 16, 2014 (p. 1). American Society of Agricultural and Biological Engineers. doi:10.13031/aim.20141911016

Matta-Gómez, A., et al. (2014). Multi-robot data mapping simulation by using microsoft robotics developer studio. Simulation Modelling Practice and Theory, 49, 305-319. https://doi.org/10.1016/j.simpat.2014.10.003

Obermeyer, Z., \& Lee, T. H. (2017). Lost in thought - the limits of the human mind and the future of medicine. New England Journal of Medicine, 377(13), 1209-1211. doi: 10.1056/NEJMp1705348

Oksanen, T., \& Backman, J. (2016). Implement Guidance model for ISO 11783 standard. IFAC-PapersOnLine, 49(16), 33-38. https://doi.org/10.1016/j.ifacol.2016.10.007

Pedersen, R. D. (2018). Motor Vehicle Artificial Intelligence Expert System Dangerous Driving Warning And Control System And Method. U.S. Patent Application 15/885,412.

Pham, X., \& Stack, M. (2018). How data analytics is transforming agriculture. Business Horizons, 61(1), 125-133. https://doi.org/10.1016/j.bushor.2017.09.011

Pobkrut, T., Eamsa-ard, T., \& Kerdcharoen, T. (2016, June). Sensor drone for aerial odor mapping for agriculture and security services. In Electrical Engineering/Electronics, Computer, Telecommunications and Information Technology (ECTI-CON), 2016 13th International Conference on (pp. 1-5). IEEE. https://doi.org/10.1109/ECTICon.2016.7561340

Reina, G., et al. (2016). Ambient awareness for agricultural robotic vehicles. Biosystems Engineering, 146, 114-132. https://doi.org/10.1016/j.biosystemseng.2015.12.010

Rokhmana, C. A. (2015). The potential of UAV-based remote sensing for supporting precision agriculture in Indonesia. Procedia Environmental Sciences, 24, 245-253. https://doi.org/10.1016/j.proenv.2015.03.032

Rupnik, R., et al. (2018). AgroDSS: A decision support system for agriculture and farming. Computers and Electronics in Agriculture. https://doi.org/10.1016/j.compag.2018.04.001

Sabarina, K., \& Priya, N. (2015). Lowering Data Dimensionality in Big Data for the Benefit of Precision Agriculture. Procedia Computer Science 48: 548-554.

https://doi.org/10.1016/j.procs.2015.04.134

Sahoo, R. N., Ray, S. S., \& Manjunath, K. R. (2015). Hyperspectral remote sensing of agriculture. Current Science, 108(5), 848-859.

Scurlock, J. T. (1976). U.S. Patent No. 3,991,583. Washington, DC: U.S. Patent and Trademark Office.

Stehr, N. J. (2015). Drones: The newest technology for precision agriculture. Natural Sciences Education, 44(1), 89-91. doi:10.4195/nse2015.04.0772 


\section{Macrothink}

Journal of Agricultural Studies

ISSN 2166-0379

2018, Vol. 6, No. 4

Thackeray, H. S. J. (1911). The Old Testament in Greek, according to the text of Codex Vaticanus: The Octateuch (Vol. 1). University Press.

Wagner, W. P. (2017). Trends in expert system development: A longitudinal content analysis of over thirty years of expert system case studies. Expert Systems with Applications, 76, 85-96. https://doi.org/10.1016/j.eswa.2017.01.028

Wolfert, S., et al. (2017). Big Data in Smart Farming - A review. Agricultural Systems, 153: 69-80. https://doi.org/10.1016/j.agsy.2017.01.023

Zhang, C., Walters, D., \& Kovacs, J. M. (2014). Applications of low altitude remote sensing in agriculture upon farmers' requests-a case study in northeastern Ontario, Canada. PloS one, 9(11), e112894. https://doi.org/10.1371/journal.pone.0112894

Zhang, Q., et al. (2019). Multisource data based agricultural drought monitoring and agricultural loss in China. Global and Planetary Change, 172, 298-306.

https://doi.org/10.1016/j.gloplacha.2018.10.017

Zisopoulos (2018). WO-2018046973-A2 Airborne pipeline docked to an earth reservoir to deliver water over long distance for aerial firefighting and irrigation. 2/9/2016 15/3/2018. https://patents.google.com/patent/WO2018046973A2/en

\section{Copyright Disclaimer}

Copyright for this article is retained by the author(s), with first publication rights granted to the journal.

This is an open-access article distributed under the terms and conditions of the Creative Commons Attribution license (http://creativecommons.org/licenses/by/4.0/). 